\title{
Que Rosto Tem Pierre Rivière? Subjetividade e memória do sujeito criminoso no cinema
}

\section{Quel Visage A Pierre Rivière? \\ La subjectivité et la memóire du sujet criminel dans le cinéma}

\author{
Cecília BARROS-CAIRO \\ Universidade Estadual do Sudoeste da Bahia - UESB \\ LABEDISCO - Laboratório de Estudos do Discurso e do Corpo \\ Nilton MILANEZ \\ Universidade Estadual do Sudoeste da Bahia - UESB \\ LABEDISCO - Laboratório de Estudos do Discurso e do Corpo
}

\begin{abstract}
RESUMO: Este artigo propõe a investigação dos processos de constituição do rosto criminoso no cinema, considerando a memória das imagens e os saberes produzidos pelo discurso fílmico como compositores de uma trama enredada na configuração de um sujeito comprometido historicamente com a desordem jurídica e social. Entendemos ser importante observar o rosto criminoso no dispositivo fílmico como acontecimento em uma rede de práticas discursivas que, em um conjunto de regras históricas determinadas no tempo e no espaço, definem e possibilitam que a cristalização desse sujeito como irregular torne-se reconhecível desde a tela do cinema até as relações sociais entre as quais todos nós existimos. Nesta presente análise apresentaremos a discussão a partir do filme Eu, Pierre Rivière, que degolei minha mãe, minha irmã e meu irmão (1976), dirigido por René Allio e baseado no livro homônimo organizado no Collège de France, em 1973, por um grupo de estudiosos sob a coordenação de Michel Foucault, trabalho este que discutiu as relações entre os saberes da Psiquiatria e da Justiça Penal na constituição e institucionalização do sujeito criminoso. Entendemos que em sua obra, Foucault produziu uma história dos diferentes modos de subjetivação do ser humano em nossa cultura e esclareceu como as subjetividades são constituídas pelo discurso e pela história, fazendo eclodir a relação entre linguagem, memória e sociedade na base desta reflexão. São de grande relevância para essa pesquisa os estudos que compreendem a memória enquanto composta por redes e trajetos que atualizam discursos e práticas historicamente constituídos, sob uma perspectiva que abre vias de associação no presente. Além do aparato conceitual foucaultiano, tomaremos como outras referências teóricas importantes os trabalhos de Jean Jacques-Courtine sobre o corpo, a história do rosto e a intericonicidade, bem como alguns aspectos pesquisados pelas teorias do cinema.
\end{abstract}

PALAVRAS-CHAVE: Rosto criminoso, subjetividade, memória, discurso, cinema.

RÉSUMÉ: Cet article propose la investigation des processus de la constituition du visage criminel dans le cinéma, en ce qui concerne la question de la mémoire des images et des connaissances produites par le discours filmique comme compositeurs d'une trame enchevêtré dans la configuration d'un sujet historiquement impliqué avec le désordre juridique et social. Nous croyons qu'il est important de noter le visage criminel dans le dispositif filmique comme un événement dans un réseau de pratiques discursives qui, dans un ensemble de règles historiques déterminées dans le temps et l'espace, définissent et permettent la cristallisation de ce sujet comme irrégulière devenu reconnaissable à l'écran cinema et aussi sur les relations sociales dans que tous nous existons. Dans la présente analyse, nous présenterons la discussion sur le film Moi, Pierre Rivière, qui égorgé ma mère, ma soeur et mon frère (1976), réalisé par René Allio et basé sur le livre homonyme organisé au Collège de France en 1973 par un groupe 
de chercheurs sous la supervision de Michel Foucault, travail qui a examiné la relation entre la connaissance de la Psychiatrie et de la Justice Pénale dans la constituition et l'institutionnalisation du sujet criminel. Nous comprenons que dans son travail, Foucault a produit une histoire des différents modes de la subjectivité de l'être humain dans notre culture et clarifié comment les subjectivités sont constitués par le discours et l'histoire, permettant l'émergence des relations entre le langage, la mémoire et la société sur la base de cette réflexion. Sont d'une grande importance à cette recherche les études qui comprennent la mémoire comme une réunion des réseaux et des chemins qui actualisent les discours et les pratiques historiquement constitués, dans une perspective qui ouvre itinéraires d'association au present. Au-delà de l'exposition conceptuel de Foucault, nous allons prendre d'autres références théoriques importantes telles que les œuvres de Jean-Jacques Courtine sur le corps, l'histoire du visage et la intericonicité, aussi bien que certains aspects recherchés par les théories du cinéma.

MOTS-CLÉS: Visage criminel, subjectivité, mémoire, discours, cinéma.

\section{Sobre o que estamos pensando...}

Neste presente trabalho, tomamos o rosto do criminoso como discurso subjetivado e corporificado no (e pelo) cinema para entender sua constituição perpassada por memórias e práticas que instauram o seu regime de existência enquanto acontecimento histórico de desordem jurídica tão pretérito quanto atual. Partindo do fato de haver laços históricos e discursivos que unem os diferentes momentos de constituição do sujeito criminoso, observamos inúmeros lugares que, na linha das dispersões históricas, (re)constroem marcas sociais subjetivas que promovem (re)aparecimentos de cadeias discursivas em recriações cotidianas. O que notamos é que, no cinema, o rosto criminoso é revelado como um mapa subjetivo da ilegalidade. Assim, a intenção desse trabalho é, justamente, compreender, a partir da análise do discurso fílmico, como a figura desse monstro moral (FOUCAULT, 2001) aparece em meio aos domínios disciplinares do saber-poder sobre o crime. Para tanto, tomamos como suporte para análise a produção fílmica Eu, Pierre Rivière, que degolei minha mãe, minha irmã e meu irmão, de 1976, dirigida por René Allio e baseada no livro homônimo organizado no Collège de France, em 1973, por um grupo de estudiosos sob a coordenação de Michel Foucault, trabalho este que discutiu as relações entre os saberes da Psiquiatria e da Justiça Penal na constituição e institucionalização do sujeito criminoso.

Entendemos que por meio dos discursos no cinema, ocorre a materialização do rosto criminoso em um mundo da noção jurídico-biológica, controlado por certo tipo de saber e poder que conduzem a sua constituição subjetiva a uma espécie de padrão determinado, reconhecido e indesejável. É considerando os recursos materiais do cinema que nos propomos à compreensão do rosto criminoso nos cercando de imagens em movimento que, ao mesmo tempo em que contam uma história, também produzem a história de quem somos nós hoje?, como anunciou a pergunta kantiana em que se inspirou Michel Foucault a fim de problematizar um diagnóstico do presente.

Neste sentido e a partir dessas considerações, acreditamos que podemos analisar o modo como agimos e pensamos tanto em relação ao sujeito na projeção fílmica quanto em relação a nós mesmos na vida real (FOUCAULT, 2004). Tal forma de ver o rosto no cinema pode ordenar uma "atualidade de saber" (FOUCAULT, 2009, p. 5) que construirá sentidos para uma narrativa sobre a forma de sermos vistos enquanto sujeitos. 
Assim, nos arriscamos a pensar que a imagem em movimento move efeitos de sentido nas discursividades materializadas como produções de verdades no sujeito que enuncia, naquele que é enunciado e no que se põe diante desse acontecimento como receptor e agente no processo de (re)elaborar o que lhe é e como lhe é apresentado.

\subsection{Por uma história do rosto criminoso no cinema}

Tomamos o estudo da história no interior da perspectiva foucaultiana, o que significa atribuir, como conceito operatório, a noção de descontinuidade (FOUCAULT, 2009) e, desse modo, verificar que os fatos se desenvolvem em um espaço de dispersões. A partir desse modo de conceber a história, tomamos como principal obra de estudos para o alcance desta presente análise, a História do rosto produzida por JeanJacques Courtine e Claudine Haroche em 1988.

Em se tratando da constituição histórica do rosto, partimos dos percursos que evidenciam as formas de sabê-lo a partir dos estudos propostos pela fisiognomonia ${ }^{1}$, ciência que buscava o conhecimento do caráter da pessoa pelos seus traços fisionômicos e pelas ciências criminológicas ${ }^{2}$, cujo principal expoente foi - e continua a ser importante referência para os estudos do Direito -, o médico e jurista italiano Cesare Lombroso.

$\mathrm{Na}$ composição do corpo biológico do ser humano, observamos que o rosto ocupa a função de identificação do sujeito. Historicamente, de uma articulação necessária entre o sujeito, a linguagem e o seu rosto, instituiu-se a necessidade de um individualismo de costumes que transformou significativamente a identidade individual, delimitando o que era da ordem do individual e do privado (ARIĖS; CHARTIER, 2009). Assim, a noção de indivíduo passou a não se dissociar do seu rosto, que expressava e traduzia no corpo a sua subjetividade. Courtine e Haroche em História do Rosto empreendem um percurso, entre os séculos XVI e XVIII, do desenvolvimento progressivo da percepção da expressão, ou seja,

Uma história da emergência da expressão e ao mesmo tempo uma história do controle da expressão, de suas exigências religiosas, de suas normas sociais, políticas e éticas que contribuíram, desde a Renascença para a aparição de um tipo de comportamento social, emocional, sentimental, psicológico fundado no distanciamento do excesso, no silenciamento do corpo (COURTINE; HAROCHE, 1994, p. 16).

Courtine e Haroche vasculham as continuidades e descontinuidades presentes na história da expressividade do rosto e de suas implicações para a percepção de si mesmo, por parte do sujeito, e para a percepção do sujeito em relação ao outro, o que afeta as relações sociais. A importância da abordagem histórica de enunciados que se repetem e se reiteram em torno da afirmação de que "pelo rosto, o indivíduo se exprime" reside na observação da relação entre o sujeito, a linguagem e o rosto (COURTINE; HAROCHE, 1994, p. 10). O processo de racionalização dos comportamentos liga-se complexamente

\footnotetext{
${ }^{1}$ Os estudos fisiognônicos tiveram como precursores Francisco Eximenos, Giambatista della Porta e Johann Kaspar Lavater.

2 Ciências também conhecidas como Antropologia Criminal ou Biologia Criminal, cujo objetivo é esclarecer a gênese do fato delituoso através de estudos dos caracteres fisio-psíquicos, juntamente com as influências externas.
} 
ao fato de que "o indivíduo é, desde então, indissociável da expressão singular de seu rosto, tradução corporal de seu 'eu' mais íntimo" (COURTINE; HAROCHE, 1994, p. 10). Daí a atenção dispensada à caracterização dos signos faciais para a compreensão daquilo que o indivíduo tem de mais particular.

A incursão pela tradição fisiognomônica como tentativa de analisar o rosto recorreu a tratados médicos e anatômicos para assegurar quando o homem devia ser autêntico ou conformar-se, exprimir-se ou apagar-se, ter espontaneidade das emoções ou silenciá-las, ou seja, tratava-se da história do corpo dos homens em sociedade. Desse modo, o rosto era tomado como uma textualidade, exprimindo uma interioridade que podia ou não mostrar- se. Assim, a fisiognomonia, cujo gosto se faz por uma "ciência do rosto", mantém-se ainda em funcionamento, sendo o rosto e o corpo os alvos de uma observação detalhada e pormenorizante. Com o objetivo de desnudar e revelar o coração, a fisiognomonia se define, então, como a "ciência das paixões naturais da alma e dos acidentes do corpo" (COCLÈS, 1.504 apud COURTINE; HAROCHE, 1994). O corpo é, ao mesmo tempo, objeto assinalado e discurso proferido, indício e palavra da alma, de maneira que os movimentos das paixões, que habitam o interior do homem, se revelam na superfície de seu corpo.

Para Courtine e Haroche (1988) o rosto é, ao mesmo tempo, metonímia da alma - a frágil porta da sua morada, o acesso como porta entreaberta para contemplá-la - e metáfora da alma - a figura da alma, sendo a fisiognomonia o repertório de uma linguagem das figuras. Os efeitos de sentido instalados pela fisiognomonia continuaram a inscrever o rosto como o espaço de visibilidade da boa ou má alma e, em consequência, como lugar de interpretação judicial e de determinação do desvio, haja vista que a psiquiatria forense ainda se vale do olhar, que perscruta e julga o homem por sua aparência para decidir sobre o crime ou a loucura.

Em 1875, Cesare Lombroso, comungando com os fisiognomonistas, escreveu $O$ homem delinquente ${ }^{3}$ partindo da ideia da completa desigualdade fundamental entre homens honestos e criminosos, estando preocupado em encontrar no organismo humano traços diferenciais que separassem e demarcassem o sujeito desviante. Segundo Lombroso, existiria um conjunto de marcas do criminoso voltado principalmente para a sua aparência, assimetria craniana, fronte fugidia, orelhas em asa, zigomas salientes, arcada superciliar proeminente, prognatismo maxilar, face ampla e larga, cabelos abundantes, dentre outras características que se apresentam regulares no rosto desse sujeito. Vejamos no filme Eu, Pierre Rivière, que degolei minha mãe, minha irmã e meu irmão como o rosto criminoso é produzido pelo dispositivo audiovisual de modo a trazer em sua superfície o que constitui sua monstruosidade moral.

\subsection{A fisiognonomia de Pierre Rivière no dispositivo audiovisual}

Pensamos a irrupção desses acontecimentos enunciativos acerca dos estudos fisiognomônicos em uma descontinuidade histórica que possibilita que o rosto criminoso exista, seja conhecido, tome forma e seja retomado, tal como então o problematizamos nesta pesquisa em uma nova materialidade: o dispositivo audiovisual. Ao olhar para o dispositivo audiovisual, estamos aludindo tanto para seus recursos e estratégias de elaboração de imagem em movimento e som quanto para os discursos e práticas que eles produzem (MILANEZ; CAIRO; BRAZ, 2013). Estamos, desse modo, entendendo tal dispositivo a partir das nossas leituras foucaultianas como um conjunto

\footnotetext{
${ }^{3}$ As conclusões de Lombroso em $O$ homem delinquente foram construções eminentemente empíricas baseadas em resultados de 386 autópsias de delinquentes e nos estudos feitos em 3939 criminosos vivos.
} 
de táticas, leis e estratégias que fazem ver, dizer e institucionalizar os sujeitos (FOUCAULT, 1985).

O camponês francês que, aos vinte anos, assassinou a golpes de foice sua mãe grávida de sete meses, Marie Anne Victorie; sua irmã de 18 anos, Victorie Rivière, e seu irmão de sete anos, Jules Rivière, preencheu as notícias de jornais e folhetins de 1835, causando repulsa e julgamento da opinião pública, aflorando a associação entre o trabalho jurídico e o psiquiátrico. Nesta presente análise, interessa-nos que na busca pela motivação e justificação de tal crime de parricídio e fratricídio, um mosaico de interpretações e verdades foram se construindo à margem do texto e do ato do sujeito confesso. Nesta direção, tanto no dossiê do caso, coordenado e produzido por Michel Foucault e sua equipe de pesquisadores, em 1973, quanto no filme dirigido por René Allio, em 1976, aparecem respostas articuladas em torno das características físicas de Rivière que definem, em meio a outros fatores, a condição do jovem criminoso.

No filme de Allio, os sinais fisiognomônicos de Rivière relatados nos registros e descritos no dossiê coordenado por Foucault são materializados por meio do dispositivo audiovisual de maneira a tornar irregular o rosto do criminoso em foco. Através do fotograma capturado de uma cena central do filme, em que Rivière, já detido pela polícia, confessa seus crimes, convidamos à análise do rosto de criminoso nos modos como foi produzido pelo dispositivo audiovisual (Figuras 1 e 1.1):

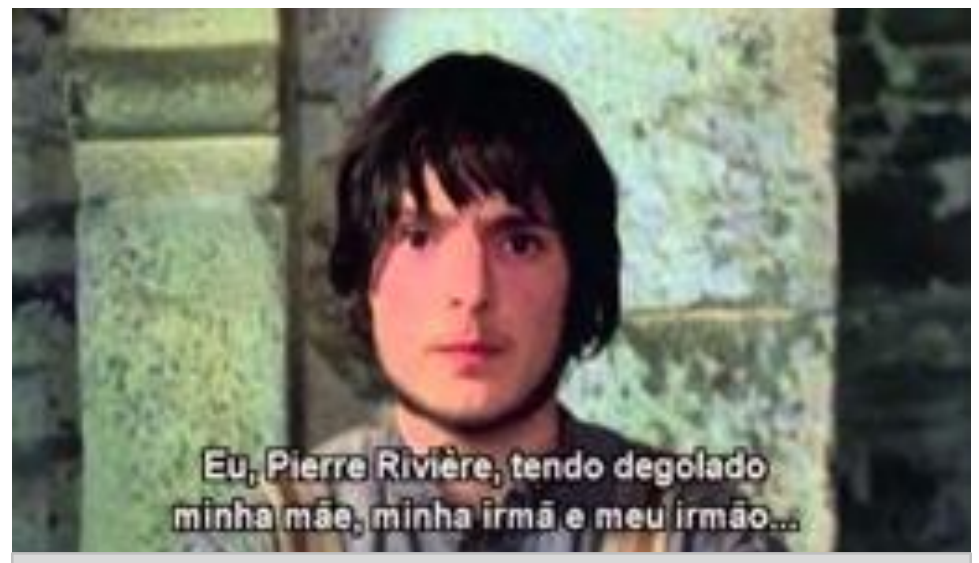

Figura 1 - Eu, Pierre Rivière, que degolei minha mãe, minha irmã e meu irmão (ALLIO, 1976).

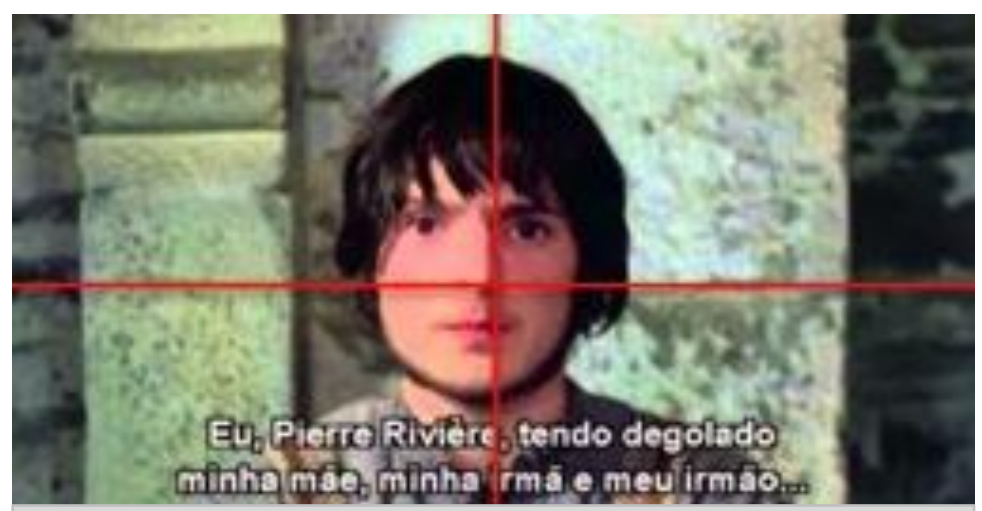

Figura 1.1 - Eu, Pierre Rivière, que degolei minha mãe, minha irmã e meu irmão (ALLIO, 1976). 
Notamos, em primeiro lugar, que a posição fixa e central da câmera com foco em Rivière elabora um portrait do criminoso. $\mathrm{O}$ retrato, aqui em movimento, nos envia à memória dos cartazes de criminosos procurados, tática utilizada pela polícia de investigação, pelos jornais e pelo que nos acostumamos a ver nos filmes de faroeste, chegando aos nossos dias com técnicas de imagem muito apuradas para a elaboração de retratos falados de suspeitos e fotografias que circulam na internet ou são manchetes de matérias jornalísticas impressas e da rede televisiva. Embora as demarcações físicas não sejam, no caso Rivière, determinantes para a sentença penal à qual foi submetido diante dos crimes que cometeu, elas são relatadas com certa minúcia, e então nos interessam tais características: "(...) sinais particulares - olhar oblíquo, cabeça inclinada, suíças negras e ralas ${ }^{4 "}$ (FOUCAULT, 2007, p. 179).

Em segundo lugar, é também a posição fixa da câmera, centralizando Rivière na tela, que nos cria o efeito de observar o seu rosto separado, descolado, adiantado em relação ao tronco. A sombra do queixo e da barba do ator sobre o seu pescoço nos dá a ver um Rivière degolador agora também degolado. Notamos, recorrendo à medida exata da tela retangular, que o nariz do criminoso, ponto central da face humana, ocupa também o centro da imagem e, possivelmente, o uso deste enquadramento nos impele a fixar o olhar sobre o rosto e os olhos de Rivière, reforçando o efeito de flutuação de sua cabeça. A anormalidade que se dá a ver na possibilidade de entender o degolamento de Rivière a partir das técnicas de imagem e movimento utilizadas faz demarcar o criminoso em sua condição de irregularidade. Procedemos nessa análise cinematográfica em âmbito discursivo, compreendendo “(...) as delicadas tiranias da mobilidade, os discretos poderes da abundância; analisando preferencialmente os efeitos de incitação do que operações de interdição; as lógicas de superinformação do que os mecanismos de censura" (COURTINE, 2003, p. 33). Esta compreensão perpassa, portanto, por uma busca pelas condições de produção do discurso e pela constituição da subjetividade do rosto criminoso que nele está diluída. Dessa forma, em meio ao cenário histórico e social que enredam o filme, tais condições de produção se compõem como linhas que fazem ver e falar o rosto criminoso como reconhecivelmente anormal. Neste sentido, a expressão da vida submetida ao poder, lembra Foucault, é produto de um processo histórico voltado para o controle da vida pessoal:

Esta forma de poder se exerce na vida quotidiana imediata, que classifica os indivíduos em categorias, os designa em sua individualidade própria, os adstringe às suas individualidades, lhes impõem uma lei de verdade que eles devem aceitar e que os outros devem reconhecer neles (FOUCAULT, 1985, p. 227).

Estamos tratando, no caso Rivière, da identificação, a partir do criminoso, de uma noção jurídico-biológica que agrupa o avesso da espécie humana na categoria do anormal. $\mathrm{Na}$ cena em análise, considerando o aparato técnico utilizado e o enquadramento, além de observarmos a cabeça de Rivière flutuante em relação ao tronco, notamos também esse efeito de anormalidade em relação aos outros elementos

\footnotetext{
${ }^{4}$ Descrição completa: "Registro de admissão de prisioneiro na Prisão Central de Beaulieu: Nome, prenome e sinais particulares dos condenados/ 7222 Riviere, Jean Pierre, filho de Pierre Marguerie e de Victoire Brion. Chegado a 7 de março de 1836 Idade -- 21 anos/ Altura -- 1m 62/ Cabelos -- negros/ Sobrancelhas -'. idem/ Testa - estreita/ Olhos -- avermelhados/ Nariz - médio/ Boca - média/ Queixo -redondo/ Rosto - oval/ Tez - morena/ Barba - castanho claro/ Sinais particulares - olhar oblíquo, cabeça inclinada, suíças negras e ralas". (FOUCAULT, 2007, p. 179).
} 
componente do quadro, tais como o cenário em profundidade de campo alta, promovendo o desfoque do fundo, e a própria posição corporal na interpretação do ator, o que garante maior evidência ao rosto de Rivière. Notamos que o efeito produzido por essa estratégia de mise-en-scène do ator é de um rosto protuberante e também de um rosto inacessível.

É também o rosto de Rivière um que não se pode ver ou um que se deseja ocultar, podendo ser remetido a um rosto mascarado. $\mathrm{O}$ rosto de Rivière, cujo adiantamento se faz em relação ao tronco, também nos leva associar um possível uso de máscara que impede que sua identidade real seja conhecida. Ao nos darmos conta de que podemos estar diante de um homem sem rosto, o efeito do desconhecido é também fomentador de um efeito monstruoso. Mais uma vez, por meio das técnicas do dispositivo audiovisual, estamos diante de um monstro moral (FOUCAULT, 2001). Observemos, mais uma vez utilizando um outro fotograma capturado (Figura 2) da mesma sequência de cenas apresentada anteriormente, como há uma aproximação da imagem do rosto de Rivière com o uso de máscaras, tomando como disparador principal dessa comparação o sombreamento que o queixo provoca em relação ao restante do corpo:

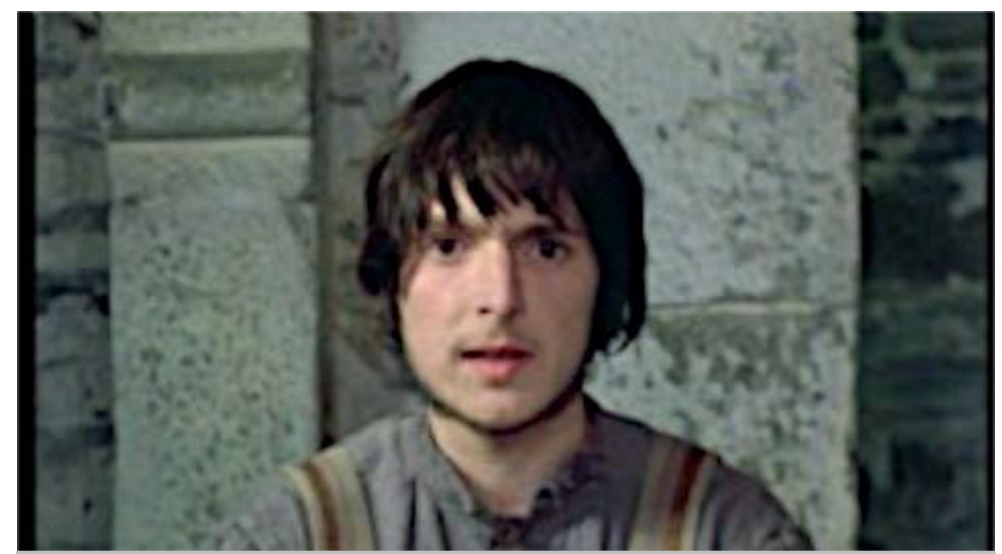

Figura 2 - Eu, Pierre Rivière, que degolei minha mãe, minha irmã e meu irmão (ALLIO, 1976).

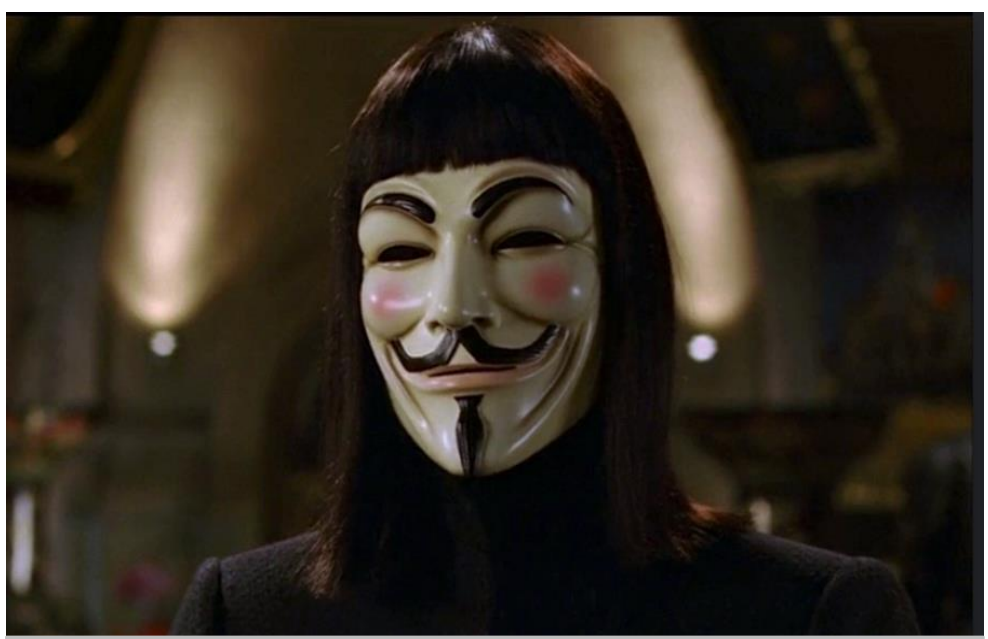

Figura 3 - V for Vendetta (James McTeigue, 2005). 
A máscara de Rivière nos aparece misteriosa como a do $V$ for Vendetta, série de romances gráficos criada em 1982 pelos britânicos Allan Moore e David Lloyd, que conta a história de um anarquista e revolucionário mascarado que tenta destruir o Estado Totalitário. Na produção fílmica originada da criação em quadrinhos, então dirigida por James McTeigue em 2005 (Figura 3), a vingança de V é direcionada àqueles que o desfiguraram em experiências de laboratório semelhantes às dos campos de concentração nazista. A máscara de Rivière é também reveladora de um sujeito que assassina sua mãe e irmãos para vingar-se pelo sofrimento que provocavam em seu pai. Por trás da máscara de $\mathrm{V}$, a monstruosidade biológica e a deformidade física; em Rivière, a máscara para uma anormalidade moral.

A máscara de Rivière é também como a máscara cadavérica da Morte Rubra do conto de Edgar Allan Poe, a máscara da peste que penetrou numa festa Real e, por sua impostura, teve a ameaça de cortarem-lhe a cabeça (POE, 1981). Como Rivière, com o "poder" de controlar fantasticamente sua cabeça flutuante e fazer ecoar, a partir de um mesmo ângulo, uma possessão de tantos discursos que produziram sua subjetividade criminosa, a Morte Rubra foi quem orvalhou todos de sangue no salão. A produção cinematográfica de Rivière também nos pinta de sangue porque, emprestando de Nietzsche (2009), a vontade de verdade está também na verdade de morte e aí existe a violência em nós, o sangue do nosso sangue, a vida-morte que pulula das nossas entranhas...

\subsection{A cabeça flutuante no cinema}

O efeito conjunto desses elementos do dispositivo audiovisual, nesta cena, transporta-nos a outras cenas, funcionando como um nó em uma rede. Assim podemos nos remeter aos tempos iniciais do cinema, com Georges Méliès ${ }^{5}$, ilusionista francês que, em 1898, produziu a filmagem Un homme de têtes (Figura 4). Na produção, Méliès separa, fácil e repetidamente, sua cabeça do pescoço. A intenção de provocar espanto e admiração no espectador é alcançada pela técnica e, em concomitância, abriga na materialidade a produção discursiva cujo efeito é da ordem do fantástico.

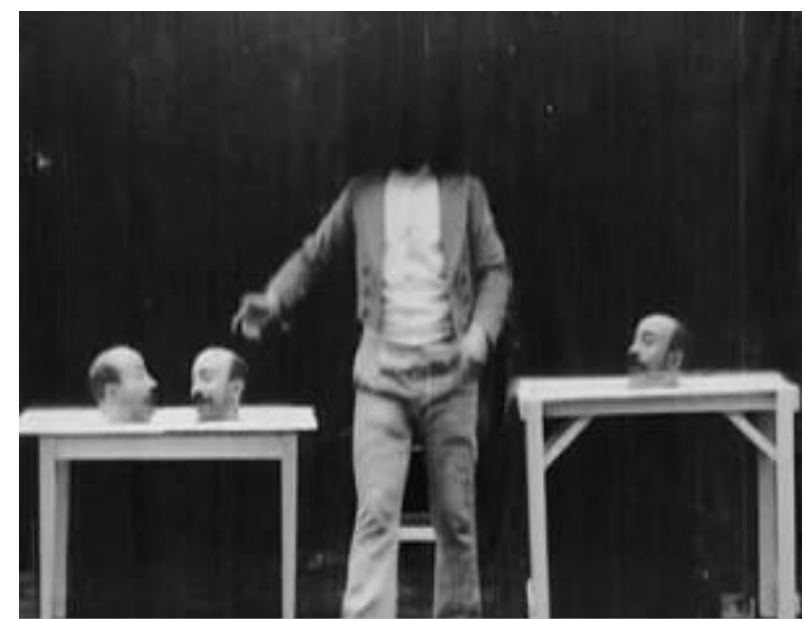

Figura 4 - Un homme de têtes (Méliès, 1898).

\footnotetext{
5 Após o primeiro contato com o trabalho dos irmãos Lumière, precursores da imagem em movimento, Méliès começa a utilizar as luzes projetadas em seus espetáculos e, ao mesmo passo, começa a pensar que adulterando cortes e películas, poderia fazer objetos sumirem diante dos olhos dos espectadores. Arrisca, assim, os primeiros efeitos especiais do cinema.
} 
Méliès mostra em seu ilusionismo o que nenhum de nós é capaz de realizar em condições comuns da vida. No filme Eu, Pierre Rivière, que degolei minha mãe, minha irmã e meu irmão, René Allio também promove, através do efeito de degolamento do criminoso por meio do dispositivo audiovisual com suas táticas e técnicas, o que a sociedade comum não é capaz, usando as próprias mãos, de fazer com um sujeito que invade suas regras morais.

Neste sentido, o que estamos querendo demonstrar é que a produção do discurso da imagem em movimento dá a ver as maneiras como os outros procedimentos discursivos a atravessam. Neste caso, estamos tratando dos discursos médico e jurídico que examinam e inquerem Rivière. Na tela de cinema, a punição do sujeito criminoso, considerado assassino e anormal, se evidencia ao executar o degolamento do criminoso. Ao olhar fixamente para o rosto projetado no centro da imagem, o efeito provocado pelo ilusionismo de Méliès de espanto e admiração é novamente promovido. Enfim, o telespectador, como uma espécie de polícia social, pode tranquilizar-se, porque o assassino teve, seguindo a lei de Talião e na tela projetada, a sua cabeça arrancada, fazendo cumprir a justiça.

Em 1977, David Lynch, diretor, roteirista, produtor e artista visual norteamericano, conhecido por seus filmes surrealistas, produziu sua primeira obra cinematográfica intitulada Eraserhead. Neste filme, como em alguns outros sequentes de Lynch, o efeito especial da cabeça degolada também aparece. Para além de ter sido categorizado como sendo do gênero de horror, Eraserhead produz efeitos dessa ordem horrorífica, mas ao passo que se mostram tão perturbadores, evidenciam também uma composição redentora no discurso audiovisual: a cabeça de Henry - personagem central do filme - cai e seu cérebro é utilizado para fabricar borrachas escolares.
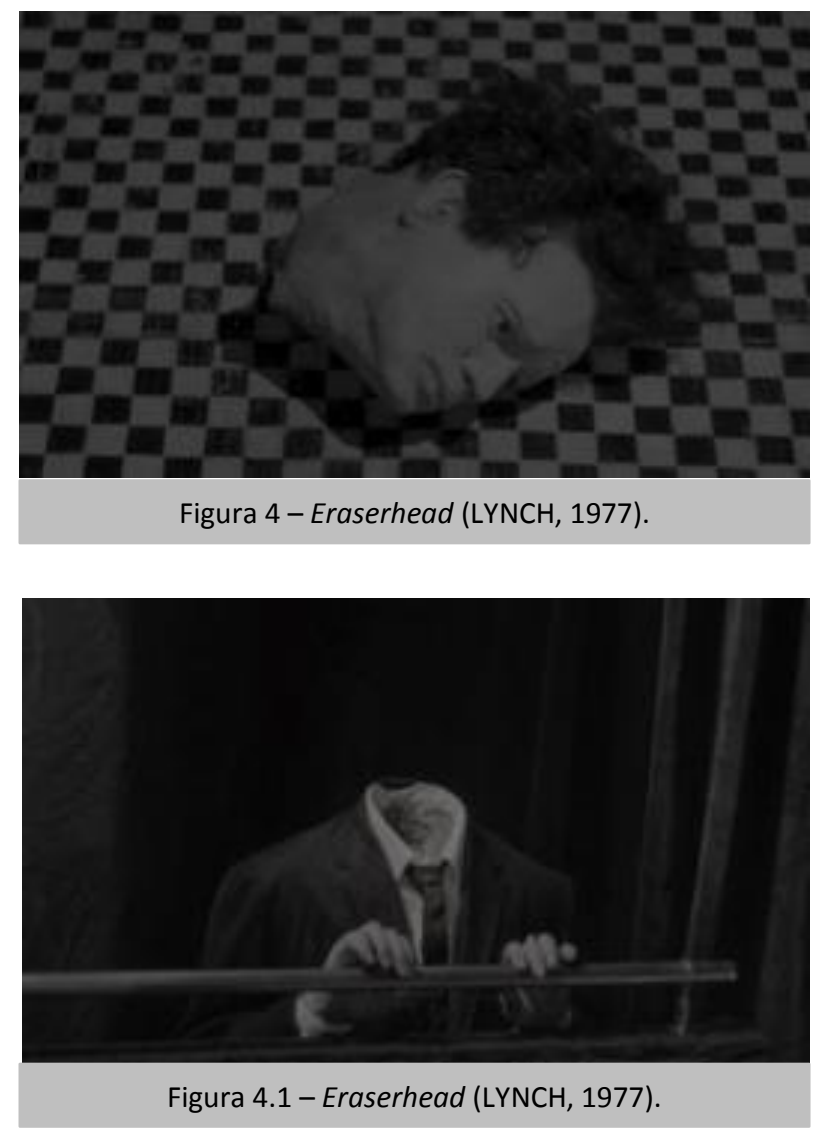
A sua cabeça de borracha decepada (Figuras 4 e 4.1) pode, enfim, apagar todos os males que aconteceram. Como afirmamos anteriormente, quando pensávamos o degolamento de Rivière no cinema, o atravessamento de discursos e práticas na materialidade audiovisual também determina de que sujeito estamos tratando e de que maneiras as composições discursivas e históricas de uma ordem jurídico-biológica controlam, regulam e definem subjetividade. A cabeça de borracha que rola pelo chão no filme de Lynch produz sentido semelhante ao efeito provocado pelo degolamento de Rivière produzido pelo dispositivo audiovisual: Enfim, livramo-nos da aberração!

\section{Subjetividade e memória do rosto criminoso - regularidades e dispersões em Pierre Rivière}

As lentes da produção cinematográfica tem o poder de explorar essa expressividade do rosto - que aprendeu, com a história, a ficar em silêncio e permanecer impassível diante de uma política atual do olhar. Em se tratando do rosto saber falar e calar, as técnicas de imagem contemporâneas tem a capacidade de potencializar essas práticas, atuando como uma espécie de arte do detalhe, assim como o faziam os tratados de fisiognomonia desde o século XVI. No caso das interpretações possíveis no cinema, pensamos que o olhar tem que ultrapassar o homem inexpressivo e explorar tecnicamente os lapsos de sua expressão.

Valendo-se desse saber acerca da interpretação das expressões e contando com o desenvolvimento tecnológico ao longo do tempo, o cinema explora não só a instantaneidade da fotografia e a possibilidade técnica de apreender uma série de instantâneos do personagem em um tempo relativamente breve - como o tempo de uma piscada, de um suspiro ou de um esboço inicial de sorriso -, mas também explora a apreensão e a exposição privilegiada dos mínimos gestos, que por mais insignificantes, ensaiados ou editados, fazem falar pelo rosto o que o verbo poderia eventualmente negar. Trata-se, portanto, de uma exploração da expressividade do rosto a partir da técnica cinematográfica que tem o poder de recortar, na descontinuidade do tempo da expressão facial, um signo corporal historicamente construído.

Em se tratando do sujeito criminoso, entendemos que para se chegar a ele é necessário que antes exista o crime, e para que o crime exista é preciso que ele seja construído. Neste sentido, consideramos que o crime não existe em uma essência e nem é ou tem um a priori. Para o crime é preciso a existência de um sujeito que o cometa e a produção de um discurso que o delimite. O crime não existe em sua objetividade, ele surge em certo contexto e a partir de certas necessidades que o possibilitam surgir enquanto uma construção discursiva. Isso nos leva a pensar que, de modo análogo, as regularidades fisiognomônicas, as marcas que definem um rosto criminoso, só podem aparecer a partir do momento que o sujeito comete o crime. É neste momento que este rosto está autorizado no campo da desordem jurídica e social passando a ser reconhecido e delimitado como tal.

Os caracteres anatômicos de Pierre Rivière relatados pelos laudos periciais, mostrados tanto no dossiê quanto no filme, certamente coadunam com as propostas da biologia criminal de Lombroso e de outros estudiosos da fisiognomonia, como Colclès ou Le Brun, e até da metoposcopia - forma medieval de ler a alma materializada no rosto (COURTINE: HAROCHE, 1994). No entanto, embora seja sedutor que essa análise assim se pudesse findar, devemos dizer que as regularidades apresentadas não nos interessam mais que as dispersões que, historicamente, podem contrariar a proposta de um rosto criminoso simplesmente suspeito por sua constituição física estrutural ou expressiva. 
O que nos dá os contornos da subjetividade de Rivière pertence ao domínio da descrição "arqueológica da constituição de um certo número de saberes sobre o sujeito" (REVEL, 2010, p. 226). A subjetividade de Rivière aparece em um momento da descontinuidade do sujeito em relação à linearidade de sua ordem. Gostaríamos, neste sentido, de entender as marcas que definem a subjetividade de Rivière no cinema e propriamente $o$ sujeito criminoso a partir de uma dispersão que pretende apreender todos os interstícios que separam os objetos, medir as distâncias que reinam entre eles e formular sua lei de repartição. Estamos propondo, assim, quadros de diferença para compreender a irrupção dessa subjetividade, ao invés de entender somente as repetições que a pudessem compor. Mesmo na função unificante de um determinado sujeito, nos adverte Foucault, a descontinuidade dos planos de suas falas e das que as atravessam, dos lugares que ocupa, faz revelar, no discurso, um conjunto em que podem ser determinadas a dispersão do sujeito e sua descontinuidade em relação a si mesmo (FOUCAULT, 2009).

No campo de regularidades, vemos condições de possibilidade para diversas posições de subjetividade. Desse modo, "não é nem pelo recurso a um sujeito transcendental nem pelo recurso a uma subjetividade psicológica que se deve definir o regime de suas enunciações" (FOUCAULT, 2009, p. 61). No caso Rivière, as formas com as quais o dispositivo audiovisual mostra o criminoso, evidencia sua anormalidade na tela, que compactua com o direcionamento da descrição fisiognomônica realizada pelas perícias médica e jurídica, fazendo compor o formato geral do criminoso. No entanto, se nos ativermos às lacunas e falhas da produção discursivo-imagética do rosto criminoso, veremos que, no regime geral ao qual obedecem os diversos modos de enunciação, as práticas, as institucionalizações e os modos de subjetividade, daremos conta do fato de que "o discurso não tem apenas um sentido ou uma verdade, mas uma história, e uma história específica que não o reconduz às leis de um devir estranho" (FOUCAULT, 2009, p. 144).

Da ordem de uma memória das imagens e recorrendo às regularidades que, discursiva e historicamente, passaram a desenhar o rosto criminoso, propomos então, na dispersão do seu acontecimento, fazer o batimento de fisionomias com características semelhantes e repetíveis a fim de refletir sobre a constituição histórica dos sujeitos em sobreposição ao seu mapeamento meramente biologicista. Estamos supondo aqui a existência de uma memória visual para os sujeitos, pois já sabemos que todo enunciado tem a sua margem povoada de outros enunciados (FOUCAULT, 2009) e, como nos ensina Courtine (2008), a memória das imagens mostra que toda imagem tem seu eco.

Podemos observar, nas imagens sequentes, como a regularidade de sinais fisiognomônicos não são capazes, em si mesmo, de delimitar o sujeito tomado como criminoso. Tomamos, como referência, o postulado lombrosiano sobre o criminoso nato, em que sinais como arcada superciliar proeminente, prognatismo maxilar, orelhas destacadas, face ampla e larga podem ser indicadores desse sujeito. 


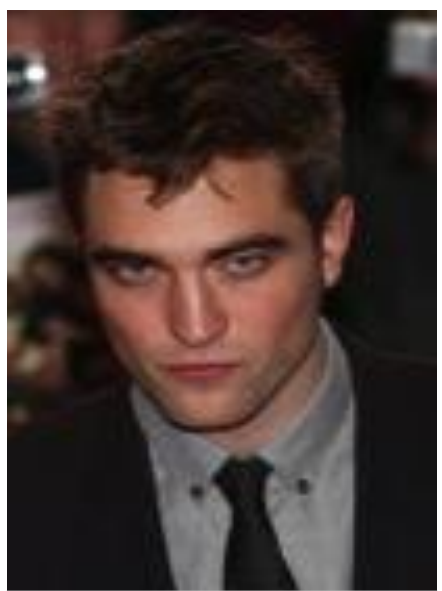

Figura 5 - Robert Pattinson Eraserhead

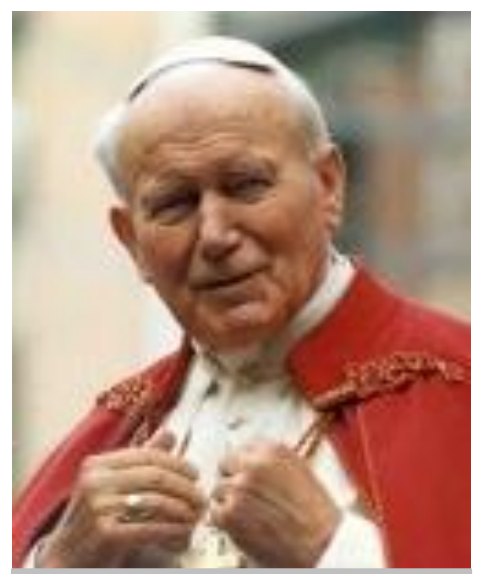

Figura 5.1 - Papa João Paulo II

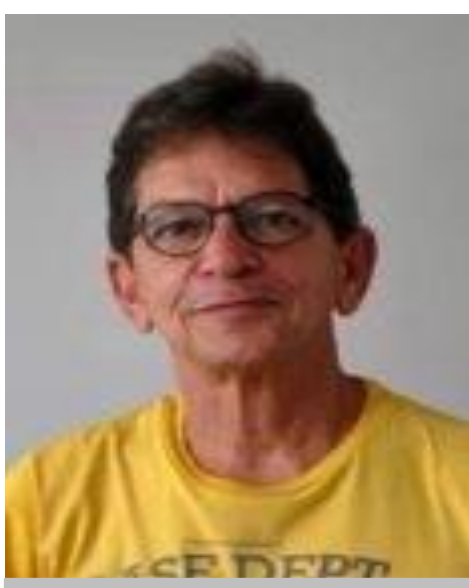

Figura 5.2 - Um homem comum

O ator Robert Pattinson (Figura 5), o papa João Paulo II (Figura 5.1) e o homem comum $^{6}$ (Figura 5.2) apresentam algum limiar de aproximação com as definições de criminoso propostas por Lombroso, no entanto, até onde sabemos, não ocupam essa posição em suas vidas. Vale considerar que, nas redes e trajetos de memórias que constituem os sujeitos, para além do fato de as ciências fisiognomônicas se valerem de subsídios sistemáticos de avaliação para uma constituição do rosto, é comum a atividade mental de visualizar corpos, vestimentas e posturas e produzir associações, por um mecanismo de repetição, que identificam quem são esses sujeitos que vemos. Assim, se alguém, no nosso contexto sócio-histórico brasileiro, por exemplo, usa roupas largas e gorro na cabeça, e se a isso se associa a cor negra de pele, possivelmente entenderemos que esse sujeito é suspeito de irregularidade, seja econômica, social ou jurídica.

\section{Inconsiderações Finais}

O rosto criminoso de Rivière, que abriga em si uma possessão de subjetividades (MILANEZ, 2009), produz determinados saberes que o enredam em torno de um julgamento e condenação por meio de um conjunto de dispositivos materiais que, segundo Courtine (2008), inscrevem o corpo em um regime particular de visibilidades, produzindo a construção desse sujeito. Dessa unidade, compreendemos regularidades e dispersões que diante de um conjunto de procedimentos que controlam a nossa maneira de viver e que determinam nossa forma de estar no mundo, permite também fazermos parte dessa engrenagem. Ao mostrar-se autor do crime e autor de sua obra - já que Rivière escreve e, no filme, verbaliza, detalhadamente, sobre sua vida e sua relação com o assassinato de sua mãe e irmãos - "o sujeito imprime o momento de irrupção única em que foge dos grilhões de sua história para reinventar-se a si” (MILANEZ, 2013), para deixar emergir sua subjetividade.

Estamos entendendo, dessa maneira, a subjetividade como "uma marca formal, moral e discursiva que brota do desejo do sujeito em contradição com as condições de harmonia que o mundo e suas relações a montaram enquanto sujeito e que foram ao longo do tempo por ela assumidas como verdadeiras" (MILANEZ, 2013, p. 377). É neste sentido que afirmamos que o ato criminoso cometido por Rivière e suas vivências como filho, irmão e carpinteiro, possibilitam, em meio às marcas de existência enredadas em suas relações de saber-poder, o sujeito ser quem ele é, ser autor de sua

\footnotetext{
${ }^{6} \mathrm{O}$ "homem comum" ao qual se refere a análise faz parte das relações pessoais de um dos autores deste presente texto, está portanto, associado a uma definição bastante subjetiva..
} 
própria invenção (REVEL, 2010, p. 228). É assim que, embora se configure como transgressor, Rivière encontra no degolamento de sua mãe, irmã e irmão o único caminho possível para a própria vida.

\section{REFERÊNCIAS}

ARIÈS, Philippe; CHARTIER, Roger (orgs). História da vida privada: da renascença ao século das luzes. Vol. 3. Tradução: Hildegard Feist. São Paulo: Companhia das Letras, 2009.

COURTINE, Jean-Jacques; HAROCHE, Claudine. História do rosto: exprimir e calar as suas emoções (do século XVI ao início do século XIX). Lisboa: Editora Teorema, 1994.

COURTINE, Jean-Jacques. Os deslizamentos do espetáculo político. In: Discurso e mídia: a cultura do espetáculo. Org: Maria do Rosário Gregolin. São Carlos: Ed. Clara Luz, 2003.

O corpo inumano. In: Corbin, A.; Courtine, J. J.; Vigarello, G. (Dir.). História do corpo: da renascença às luzes. Vol.1. Petrópolis, RJ: Vozes, 2008

FOUCAULT, Michel. Microfísica do Poder. Tradução de Roberto Machado. Rio de janeiro: Graal, 5 ed. 1985. 2001.

Os Anormais. Curso no Collège de France (1974-1975). São Paulo: Martins Fontes,

A hermenêutica do sujeito. Curso do Collège de France, 1981-1982. São Paulo: Martins Fontes, 2004.

Eu, Pierre Rivière, que degolei minha mãe, minha irmã e meu irmão. Rio de Janeiro: Graal, 2007.

A arqueologia do saber. $7^{\text {a }}$ edição. Rio de Janeiro: Forense Universitária, 2009.

LOMBROSO, Cesare. O homem delinquente. Tradução: Sebastião José Roque. Coleção fundamentos do Direito. São Paulo: Ícone, 2007.

MILANEZ, Nilton. O corpo é um arquipélago. In: NAVARRO, Pedro (org.). Estudos do Texto e do Discurso. Mapeando conceitos e métodos. São Carlos: Claraluz, 2006, p. 153179.

A possessão da subjetividade. In: SANTOS, João Bosco Cabral dos (org.). Sujeito e subjetividades: discursividades contemporâneas. Uberlândia: EDUFU, 2009.

A dessubjetivação de Dolores: escrita de discursos e misérias do corpo-espaço. In: Linguagem, Estudos e Pesquisas. UFG, Vol. 17, nº 2, Catalão, p. 367-390, 2013.

MILANEZ, BARROS-CAIRO, BRAZ. O dispositivo audiovisual - Percursos de uma construção teórico-analítica. In: FERNANDES JUNIOR, Antônio e SOUSA, Kátia Menezes de (org.). Dispositivos de poder em Foucault: práticas e discursos da atualidade. Goiânia: Editora UFG, 2013.

NIETZSCHE, Friedrich W. A genealogia da moral. Trad. Antônio Carlos Braga. 3.ed. São Paulo: Editora Escala, 2009.

POE, Edgar Allain. Contos de terror, mistério e morte. Rio de Janeiro: Nova Fronteira, 1981.

REVEL, Judith. Foucault. Conceitos essenciais. Trad. Nilton Milanez e Carlos Piovezani, 2005 .

Foucault. Une pensée du discontinu. Paris: Fayard, 2010. 